\title{
Preparation of Starch Nanoparticles in a New Ionic Liquid-in-Oil Micro- emulsion
}

\author{
Luo Zhigang $^{1 *}$, She Linrong ${ }^{2}$ and Zhan Meina ${ }^{2}$ \\ ${ }^{1}$ Carbohydrate Lab, School of Food Science and Engineering, South China University of Technology, Guangzhou, China \\ ${ }^{2}$ Heng Sheng Wei Jia Food Industry Co., Ltd, Chaozhou, China
}

\begin{abstract}
In this work, a new room-temperature ionic liquid 1-hydroxypropyl-3-methylimidazolium acetate ([C $\left.\left.\mathrm{C}_{3} \mathrm{OHmim}\right] \mathrm{Ac}\right)$ was synthesized to dissolve starch and substitute for polar phase to form $\left[\mathrm{C}_{3} \mathrm{OHmim}\right] \mathrm{Ac} / \mathrm{TX}-100+1$-butanol/cyclohexane microemulsions. The molecular structure of $\left[\mathrm{C}_{3} \mathrm{OHmim}\right] \mathrm{Ac}$ was confirmed by means of $1 \mathrm{H}$ nuclear magnetic resonance ( $\left.{ }^{1} \mathrm{HNMR}\right)$ and electrospray ionization masss pectrometry (ESI-MS). Pseudo-ternary phase diagram, conductivity measurement and dynamic light scattering (DLS) were used to analyze the microregion of IL/O micro-emulsion. Starch nanoparticles were prepared in this novel IL/O micro-emulsion with octenyl succinic anhydride (OSA) maize starch as the raw material and epichlorohydrin as the cross-linker. Fourier transform infrared spectroscopy (FTIR) data demonstrated the formation of crosslinking bonds in starch molecules. The spectrum of XRD suggested that the crystal structure of starch was destroyed. Scanning electron microscopy (SEM) and dynamic light scattering (DLS) both intuitively revealed that starch nanoparticles had good sphericity, small size and a relatively concentrated size distribution with the mean diameter of starch nanoparticles $105 \mathrm{~nm}$.
\end{abstract}

Keywords: Ionic liquid; Ionic liquid micro-emulsion; Cross-linking; Starch nanoparticle

\section{Introduction}

As one of the most abundant natural materials, starches have their own merits like renewable, biodegradable, cost-effective. However, when applied to food and ppharmaceutical fields, native starches usually need to be modified through physical, chemical, or enzymatic methods to overcome some limitations such as low thermal resistance, poor processability and solubility [1-4]. Among these starch derivatives, cross-linked starch microspheres, have attracted great interests due to their high resistance towards swelling, high shear, compression and acidic conditions and also have been one of the most investigated drug carriers for their biodegradability, biocompatibility, non-toxicity as well as high surface area [4-10].

In the last decade, papers have reported the preparation of cross-linked starch microspheres relying on solvent evaporation, precipitation and spray drying or emulsion-crosslinking techniques. Among these methods, water-in-oil (W/O) micro-emulsion has been thought as the economic and convenient template for preparing starch microsphere. There into Mao et al. reported the preparation of starch microspheres with the mean diameter ranging from 30 to $60 \mu \mathrm{m} \mathrm{[11-}$ 14]. Mao et al. estimated the average diameter of the micro-particles synthesized by W/O emulsification-cross linking method to be $50 \mu \mathrm{m}$ [14]. However, excessively large size and broad size distribution of starch microspheres have always been the problems in the traditional W/O emulsion cross-linking technique, which not only increase the risk of merging or rupturing of microspheres in tableting, but also limit the uniform and sustained release in drug delivery. In this context, there is a strong incentive to develop a new strategy for the synthesis of starch nano-sized particles with a narrow size-distributed region and research their drug delivery properties [10-12].

In recent years, room-temperature ionic liquids (ILs) have been considered as possible green and effective replacements for polar phase, non-polar phase or surfactant to prepare ionic liquid micro-emulsions, and synthesis of various inorganic particles in IL micro-emulsions system have been studied. Nevertheless, due to the structural complexity and diversity, the meticulous study on formation of starch microspheres using ILs micro-emulsion system have rarely been explored, much less for nanoparticles. In the previous reports by our group, much progresses in applying ILs into starch chemistry have been acquired in terms of dissolution and esterification of starch. These works show that ILs containing $\mathrm{Cl}^{-1}, \mathrm{Ac}^{-1}$ and $\mathrm{NO}_{3}$ 1 anions, like 1-butyl-3-methylimidazolium chloride $([\mathrm{Bmim}] \mathrm{Cl})$, 1-ethyl-3-methylimidazolium acetate ([Emim]Ac) and 1-octyl-3methylimidazolium acetate $([\mathrm{Omim}] \mathrm{Ac})$, can dissolve starch by destroying the crystalline structure and disrupting hydrogen bonding among hydroxyl groups of polymers effectively. Thereby, it enlightened us that the resulting stable and uniform dispersion of starch molecules in suitable ILs is capable of creating the excellent environment for the formation of starch nanoparticles. Accordingly, ILs with good dissolubility to starch is a prerequisite for establishing the starch nanoparticles [14].

In this work, a new room-temperature ionicliquid 1-hydroxypropyl3-methylimidazolium acetate $\left(\left[\mathrm{C}_{3} \mathrm{OHmim}\right] \mathrm{Ac}\right)$ based on the hydroxyfunctionalized imidazolium cation was tailor-made, which was the first reported by us to dissolve starch, and its molecular structure was systematically confirmed by means of ${ }^{1} \mathrm{H}$ nuclear magnetic resonance ( $\left.{ }^{1} \mathrm{HNMR}\right)$ and electrospray ionization mass spectrometry (ESI-MS). Then the new IL acted as the polar phase, combining surfactant polyethylene glycol octylphenol ether (TX-100), cosurfactant 1-butanol and oil phase cyclohexane, to prepare $\left[\mathrm{C}_{3} \mathrm{OHmim}\right] \mathrm{Ac} / \mathrm{TX}-100+1-$ butanol/cyclohexane nonaqueous ionic liquid micro-emulsions. Different techniques were used to characterize the microstructure of micro-emulsions, including pseudo-ternary phase diagram,

*Corresponding author: Luo Zhigang, Professor, School of Food Science and Engineering, South China, University of Technology, Guangzhou, China, Tel: +8620-87113845; E-mail: zhgluo@scut.edu.cn

Received October 25, 2017; Accepted November 05, 2017; Published November 15, 2017

Citation: Zhigang L, Linrong S, Meina Z (2017) Preparation of Starch Nanoparticles in a New lonic Liquid-in-Oil Micro-emulsion. J Formul Sci Bioavailab 1: 116

Copyright: $\odot 2017$ Zhigang L, et al. This is an open-access article distributed under the terms of the Creative Commons Attribution License, which permits unrestricted use, distribution, and reproduction in any medium, provided the original author and source are credited. 
conductivity measurement and dynamic light scattering (DLS). Starch nanoparticles were prepared in this novel IL/O micro-emulsion with OSA maize starch as the raw material, epichlorohydrin as the crosslinker and characterized by Fourier transform infrared spectroscopy (FTIR), X-ray diffraction (XRD), scanning electron microscopy (SEM) and DLS. Finally, drug loading and releasing properties of starch nanoparticles were investigated with indomathacin as a drug model $[15,16]$.

\section{Material and Methods}

\section{Materials}

1-Methylimidazole, 1-Chloro-3-hydroxypropane was purchased from Aladdin Chemical Reagent Company (Shanghai, China). Native maize starch was obtained from ChangChun DaCheng Maize Products Co. (Changchun, China). TX-100 was obtained from Sinoparm Chemical Reagent Co., Ltd (Shanghai, China). OSA was purchased from Gutian Chemical Engineering Co., Ltd (Nanjing, China). All other chemicals were of analytical grade [17].

\section{Synthesis of ionic liquid $\left[\mathrm{C}_{3} \mathrm{OHmim}\right] \mathrm{Ac}$}

$\left[\mathrm{C}_{3} \mathrm{OHmim}\right] \mathrm{Ac}$ was prepared in two steps (Figure 1). 1-methylimidazole $(0.5 \mathrm{~mol})$ and 1-Chloro-3-hydroxypropane $(0.6$ mol) were added in three-neck round flask with a reflux condenser for $12 \mathrm{~h}$ at $70^{\circ} \mathrm{C}$ with stirring under nitrogen. The reaction solution was cooled to room temperature and washed with ethyl acetate for three times. The bottom phase was collected, heated at $70^{\circ} \mathrm{C}$ for $12 \mathrm{~h}$ to get intermediate 1-hydroxypropyl-3-methylimidazolium chloride $\left(\left[\mathrm{C}_{3} \mathrm{OHmim}\right] \mathrm{Cl}\right)$. After that, potassium acetate $(0.34 \mathrm{~mol})$ and $\left[\mathrm{C}_{3} \mathrm{OHmim}\right] \mathrm{Cl}(0.28 \mathrm{~mol})$ were dissolved in right amount of methanol, the mixture was stirred at $25^{\circ} \mathrm{C}$ for $24 \mathrm{~h}$. After reaction, the solid was removed by negative-pressure filtration and methanol was removed under vacuum. The residue was washed with diethyl ether to remove the unreacted potassium acetate under reduced pressure. The product were heated at $50^{\circ} \mathrm{C}$ for $24 \mathrm{~h}$ to get $\left[\mathrm{C}_{3} \mathrm{OHmim}\right] \mathrm{Ac}$ with $91 \%$ of yield.

The structure of ionic liquid $\left[\mathrm{C}_{3} \mathrm{OHmim}\right] \mathrm{Ac}$ was characterized by ${ }^{1} \mathrm{HNMR}$ and ESI-MS as follows. The ${ }^{1} \mathrm{H}-\mathrm{NMR}$ spectra were obtained with an Avance III $600 \mathrm{MHz}$ digital NMR spectrometer using DMSO as solvent. The ESI-MS spectrum was obtained under positive ion mode by using Electro-spray mass spectrometry [18].

\section{Preparation of ionic liquid micro-emulsions}

To prepare $\left[\mathrm{C}_{3} \mathrm{OHmim}\right] \mathrm{Ac} / \mathrm{TX}-100+1$-butanol/cyclohexane ionic liquid micro-emulsions, certain amount of $\left[\mathrm{C}_{3} \mathrm{OHmim}\right] \mathrm{Ac}$ and cyclohexane weighted by an analytical balance $(\mathrm{d}=0.0001 \mathrm{~g}, \mathrm{FA} 1104 \mathrm{~N}$, Shanghai Balance Instrument Co., Shanghai, China) were added in a small beaker, then the mixture of surfactant TX-100 and cosurfactant 1-butanol with the mass ratio at 1 to 1 was added into the solution until the turbid solution became homogeneous and transparent.

\section{Pseudo-ternary phase diagram}

The phase behavior of $\left[\mathrm{C}_{3} \mathrm{OHmim}\right] \mathrm{Ac} / \mathrm{TX}-100+1$-butanol/ cyclohexane micro-emulsions system was determined at $25^{\circ} \mathrm{C}$ by direct observation method. Series of the micro-emulsions were prepared by fixing weight ratio of $\left[\mathrm{C}_{3} \mathrm{OHmim}\right] \mathrm{Ac} /$ cyclohexane at 9:1, 8:2, $7: 3,6: 4,5: 5,4: 6,3: 7,2: 8,1: 9$, and shaken sharply in a vortex mixer. After thermal equilibrium, the mixture of surfactant TX-100 and cosurfactant 1-butanol was added drop by drop until the phase transition was observed from turbidity to transparency [19-21].

\section{Conductivity measurement}

Conductivity of ionic liquid micro-emulsions were measured by means of a conductometer (DDS-307, Shanghai Precision Scientific Instrument Co., Shanghai, China) at $1 \mathrm{kHz}$ using a dip-type cell of cell constant $0.971 \mathrm{~cm}^{-1}$. TX-100 and 1-butanol were mixed by the mass ratio of 1:1, which was used as surfactant. The cyclohexane was progressively added into the mixture of surfactant and $\left[\mathrm{C}_{3} \mathrm{OHmim}\right] \mathrm{Ac}$, and the conductivity was measured after shaken in a vortex mixer. The errors in the conductance measurements were $\pm 0.5 \%$.

\section{Preparation of OSA modified maize starch}

Amount of native maize starch (dry weight) was suspended in distilled water $(35 \%, \mathrm{w} / \mathrm{w})$ with agitation at $35^{\circ} \mathrm{C}$. The $\mathrm{pH}$ of the mixture was adjusted with a pH controller (Model 501-3400, Barnant Co.) at $8.5-9.0$ by adding $3 \% \mathrm{NaOH}$ solution. $3 \%$ (based on dry starch dry) of OSA was added slowly within $2 \mathrm{~h}$ while controlling the $\mathrm{pH}$ at 8.59.0. After adding OSA, the reaction continued for another $1 \mathrm{~h}$. After reaction, the mixture was adjusted to $\mathrm{pH} 6.5$ with $3 \% \mathrm{HCl}$ solution, and then centrifuged and washed twice with distilled water and twice with $95 \%(\mathrm{v} / \mathrm{v})$ ethanol. The sample was oven-dried at $40^{\circ} \mathrm{C}$ for $24 \mathrm{~h}$ and then passed through a 100-mesh nylon sieve.

Determination of the Degree of Substitution (DS): The DS of OSA starch was measured by titration. OSA starch ( $5 \mathrm{~g}$, dry starch basis) was accurately weighted and suspended in $25 \mathrm{~mL}$ of $2.5 \mathrm{~mol} / \mathrm{L} \mathrm{HCl}-$ isopropyl alcohol solution by stirring $30 \mathrm{~min}$. Then $100 \mathrm{~mL}$ of $90 \%$ isopropyl alcohol solution ( $\mathrm{v} / \mathrm{v})$ was added and stirred for a further $10 \mathrm{~min}$. The suspension was filtered through a glass filter, then the residue was washed with $90 \%$ isopropyl alcohol solution until no $\mathrm{Cl}^{-}$could be detected by using $0.1 \mathrm{~mol} / \mathrm{L} \mathrm{AgNO}_{3}$ solution. The starch was re-dispersed in $300 \mathrm{~mL}$ of distilled water and heated in a boiling water bath for $20 \mathrm{~min}$. The starch solution was titrated with $0.1 \mathrm{~mol} / \mathrm{L}$ standard $\mathrm{NaOH}$ solution using phenolphthalein as an indicator. A
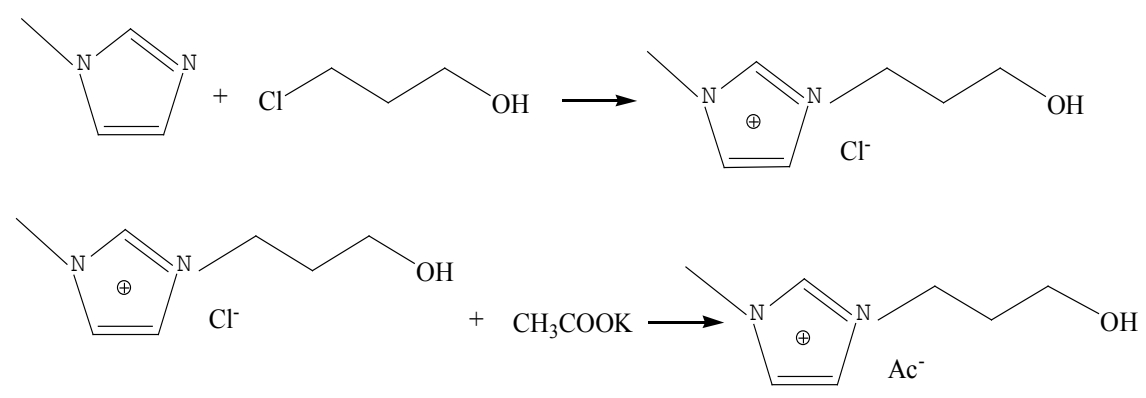

Figure 1: Preparation of ionic liquids $\left[\mathrm{C}_{3} \mathrm{OHmim}\right] \mathrm{Ac}$ by two-step method. 
blank was simultaneously titrated with native corn starch as a sample. The DS was calculated as follow:

$$
D S=\frac{0.162 \times(A \times M) / W}{1-[0.209 \times(A \times M) / W]}
$$

where $\mathrm{A}$ is the titration volume of $\mathrm{NaOH}$ solution $(\mathrm{mL}), \mathrm{M}$ is the molarity of $\mathrm{NaOH}$ solution, $\mathrm{W}$ is the dry weight $(\mathrm{g})$ of the OSA starch. According to the calculation, the DS of the modified starch was 0.018 [22].

\section{Preparation of starch nanoparticles}

Starch nanoparticles were produced by $\left[\mathrm{C}_{3} \mathrm{OHmim}\right] \mathrm{Ac} / \mathrm{TX}-$ 100+1-butanol/cyclohexane ionic liquid micro-emulsions cross-liking method with OSA starch as the raw material and epichlorohydrin as the cross-linker. Dried OSA starch was dissolved into [ $\left.\mathrm{C}_{3} \mathrm{OHmim}\right]$ Ac at a concentration of $2 \%(\mathrm{w} / \mathrm{w})$ in a three-neck round flask which was full of gaseous $\mathrm{N}_{2}$, the mixture was stirred by mechanical agitation (JB90-B, Shanghai Standard Model Co., Shanghai, China) at $90^{\circ} \mathrm{C}$ for $3 \mathrm{~h}$ to prepare the water phase. Then cyclohexane was added into the water phase with a mass ratio of 7 to $1,45 \%(w / w)$ of the mixture of TX100 and 1-butanol with the mass ratio of 1:1 was added subsequently to bulid IL/O micro-emulsion. After stirring for several minutes, $2 \%$ $(\mathrm{w} / \mathrm{w})$ epichlorohydrin was added to the micro-emulsion as a crosslinker agent. In this stage, the reaction was controlled at the condition of $50^{\circ} \mathrm{C}$ for $3 \mathrm{~h}$. The resulted micro-emulsion was cooled to the room temperature, and then starch nanoparticles were precipitated by anhydrous ethanol and centrifuged. The residue was washed with sufficient anhydrous ethanol to eliminate IL, cyclohexane, TX-100, 1-butanol and unreacted epichlorohydrin. Finally, the product was obtained after dried at $40^{\circ} \mathrm{C}$ for $24 \mathrm{~h}$. In addition, starch nanoparticles with different particle sizes could be obtained through changing the reaction conditions such as reaction time, reaction temperature, and starch concentration [23-25].

\section{Characterization of starch nanoparticles}

The structuralal characteristics of native maize starch, OSA starch and starch nanoparticles was evaluated by FTIR spectroscopy. For FTIR measurement, the samples were mixed with dried $\mathrm{KBr}$ and then compressed into thin disk-shaped pellets. The wave numbers of FTIR spectra ranged from 400 to $4000 \mathrm{~cm}^{-1}$ with a resolution of $1 \mathrm{~cm}^{-1}$.

$\mathrm{X}$-ray diffraction (XRD) technique was used to analyze the crystal structure of native maize starch, OSA starch and starch nanoparticles. XRD spectra was obtained on a X-ray diffractometer (D/Max2200, Bruke Co., Germany) with $\mathrm{Cu}$ Ka radiation $(\lambda=0.154 \mathrm{~nm})$ at $40 \mathrm{kV}$ and $40 \mathrm{~mA}$, the scattering angle rang $(2 \theta)$ was $0 \sim 60^{\circ}$ at a scatting speed of $0.02^{\circ} / \mathrm{min}$

The morphology of native maize starch, OSA starch and starch nanoparticles were characterized through Scanning electron microscopy (Merlin scanning electron microscope, Zeiss Co., Germany). All the samples were gold coated before morphology observation.

Laser light diffraction technique was used to evaluate the particle size and particle size distribution of starch nanoparticles. $0.05 \mathrm{~g}$ starch nanoparticles were dispersed in $100 \mathrm{~mL}$ distilled water and treated by ultrasound for 30 min before measurement to prevent agglomeration [26-28].

\section{Standard Curves of indomathacin}

Standard curves of indomathacin were obtained using the following approaches: $0.05 \mathrm{~g}$ of indomathacin was fully dissolved in
$25 \mathrm{ml}$ anhydrous ethanol, then diluted to $500 \mathrm{ml}$ with phosphatebuffered saline (PBS, $0.2 \mathrm{~mol} / \mathrm{L}, \mathrm{pH} 7.4$ ). The obtained $0.01 \mathrm{mg} /$ $\mathrm{mL}$ of indomathacin in PBS solution was scanned at wavelengths between 190 and $550 \mathrm{~nm}$ with a model TU-1810 ultraviolet-visible spectrophotometer (Beijing Puxi General Apparatus Co., Ltd., Shanghai, China). The wavelength at which indomathacin absorbed the most was selected as the testing wavelength for later experiments, then $0.01,0.02,0.03,0.04$, and $0.05 \mathrm{mg} / \mathrm{mL}$ of indomathacin in PBS solution were measured at the corresponding testing wavelengths to obtain the standard curve of indomathacin absorbance to concentration.

\section{Drug loading analysis}

About $50 \mathrm{mg}$ of starch nanoparticles with diameters were weighed and suspended in $20 \mathrm{~mL}$ of PBS solution with $0.02,0.04,0.06$, and 0.08 $\mathrm{mg} / \mathrm{mL}$ indomathacin each. The resulting suspensions were gently stirred at the desired temperature of $17,27,37$, and $47^{\circ} \mathrm{C}$ for $0.5,1$, $1.5,2$ and $2.5 \mathrm{~h}$. Subsequently, the solutions were centrifuged, and each supernatant was extracted to determine the drug loading and encapsulation efficiency with an ultraviolet-visible spectrophotometer according to the standard curve of indomathacin absorbance to concentration. The drug loading (A) and encapsulation efficiency (B) were calculated with eqns. (2) and (3), respectively.

$$
\begin{aligned}
& A=\left(C_{0}-C_{1} V_{1}\right) V_{0} / W \\
& B=\left(C_{0}-C_{1} V_{1}\right) / C_{0}
\end{aligned}
$$

where $\mathrm{C}_{0}$ means initial concentration of indomathacin in PBS solution, $\mathrm{C}_{1}$ means diluted concentration of indomathacin in PBS solution, $\mathrm{V}_{1}$ means dilution volume of extracted supernatant, $\mathrm{V}_{0}$ means initial volume of PBS solution, and W means the weight of starch nanoparticles dissolved in PBS solution.

\section{Drug release analysis}

About $50 \mathrm{mg}$ of drug-loaded starch nanoparticles that possess the most drug loading $(2.6 \mathrm{mg} / \mathrm{g})$ under the experimental conditions above was weighed and added to the dialysis tube. Then, $10 \mathrm{~mL}$ of PBS solution was added to the dialysis tube. Subsequently, the drug-loaded starch nanoparticles and dialysis tube were placed in a beaker containing 80 $\mathrm{mL}$ of PBS solution and slowly stirred in magnetic stirring apparatus at $37^{\circ} \mathrm{C}$. At appropriate time intervals, $5 \mathrm{~mL}$ of solution was taken out and replaced by the same volume of fresh PBS solution. The cumulative release rate was determined according to the standard curve of indomathacin absorbance to concentration and eqn. (4).

$$
Q=\frac{\sum_{n=1}^{i} C_{i} V_{i}+C_{n} V}{W \times P}
$$

where $\mathrm{Ci}$ and $\mathrm{C}_{\mathrm{n}}$ is the mass of indomathacin released from drug-loaded starch nanoparticles at a given time, $\mathrm{V}_{\mathrm{i}}$ is the solution volume got taken out at each time, $\mathrm{V}_{\mathrm{i}}=5 \mathrm{ml} . \mathrm{V}$ is the cumulative solution volume got taken out, $\mathrm{P}$ is the total drug loading in starch nanoparticles. $\mathrm{W}$ is the mass of starch nanoparticles, $\mathrm{W}=50 \mathrm{mg}$.

\section{Statistical analysis}

All of the sample analyses were conducted in triplicate and the values were expressed as means \pm standard error of the mean, statistical analysis were done using SPSS 18.0. Duncan's multiple range tests were used to estimate significant differences among means at a probability level of 0.05 [29-31]. 


\section{Results and Discussion}

\section{Structural characterization of $\left[\mathrm{C}_{3} \mathrm{OHmim}\right] \mathrm{Ac}$}

The ${ }^{1} \mathrm{H}$-NMR spectrum was employed to confirm the structure of $\left[\mathrm{C}_{3} \mathrm{OHmim}\right] \mathrm{Ac}$, as shown in Figure $1 .{ }^{1} \mathrm{H}$ NMR $(600 \mathrm{MHz}$, DMSO, $\left.25^{\circ} \mathrm{C}\right): \delta=9.83(\mathrm{~s}, 1 \mathrm{H}), 7.81(\mathrm{~d}, 1 \mathrm{H}), 7.71(\mathrm{~d}, 1 \mathrm{H}), 4.26(\mathrm{t}, 2 \mathrm{H}), 3.86(\mathrm{~s}$, $3 \mathrm{H}), 3.37(\mathrm{~s}, 1 \mathrm{H}), 2.50(\mathrm{~m}, 2 \mathrm{H}), 1.88(\mathrm{~m}, 2 \mathrm{H}), 1.59(\mathrm{~s}, 3 \mathrm{H})$. The ESIMS technique was used to obtain the molecular weight of the objective product $\left[\mathrm{C}_{3} \mathrm{OHmim}\right] \mathrm{Ac}$, and the result of the spectrum is shown in Figure 2. $\left[\mathrm{C}_{3} \mathrm{OHmim}\right]^{+}$was detected under the positive ion mode and the mass-to-charge radio $(\mathrm{m} / \mathrm{z})$ was 141.1 , which was consistent with the theoretical calculation result (141) of the molecule ion weight for $\left[\mathrm{C}_{3} \mathrm{OHmim}\right]^{+}$. The results of ${ }^{1} \mathrm{H}$ NMR and ESI-MS indicated that the $\left[\mathrm{C}_{3} \mathrm{OHmim}\right] \mathrm{Ac}$ was synthesized in two steps successfully.

\section{Phase behaviour}

The phase behaviour is essential to study micro-emulsion. Figure 2 shows the phase diagram of $\left[\mathrm{C}_{3} \mathrm{OHmim}\right] \mathrm{Ac} / \mathrm{TX}-100+1$-butanol/ cyclohexane micro-emulsions system at $25^{\circ} \mathrm{C}$. A phase boundary line could be seen to separate two-phase region and a single-phase region. It was evident that a stable, clear and transparent single-phase microemulsion region could be observed in the range of $\left[\mathrm{C}_{3} \mathrm{OHmim}\right] \mathrm{Ac}$ or cyclohexane content from $0 \%$ to $100 \%$ (wt) and it was suitable to study the microstructure of the micro-emulsions.

Apparently, a large single region that extends from [Omim]Ac starch corner to the cyclohexane corner was observed. The blank region was the one-phase micro-emulsion, and the shadow region marked "two phase" was a cloudy region. And a continuous stable single-phase micro-emulsion region could always be observed in the range of the [Omim] Ac-starch or cyclohexane content from $0 \%$ to $100 \%$ wt [32].

\section{Conductivity measurement}

It is well known that the applications of micro-emulsion depend on its structure. Therefore, it is essential to investigate the structure of micro-emulsion. Conductivity is frequently used to investigate structure and structural changes in micro-emulsions [16,25]. In the $\left[\mathrm{C}_{3} \mathrm{OHmim}\right] \mathrm{Ac} / \mathrm{TX}-100+1$-butanol/cyclohexane micro-emulsion, one- phase region can be divided into $\left[\mathrm{C}_{3} \mathrm{OHmim}\right] \mathrm{Ac} / \mathrm{cyclohexane}$ region (marked IL/O), bicontinuous region (marked B) and cyclohexane/ $\left[\mathrm{C}_{3} \mathrm{OHmim}\right] \mathrm{Ac}$ region (marked $\mathrm{O} / \mathrm{IL}$ ), corresponding to the sharp rise, flat and the drop of last in conductivity curve, respectively [26]. As shown in Figure 3, the initial conductivity increased with the increase of the weigh fraction of cyclohexane because of the continuous increase of conductive micro-emulsion droplets, indicating the formation of $\mathrm{O} / \mathrm{IL}$ micro-emulsions. When reaching a maximum, the nonlinear conductivity decrease revealed that the medium underwent a structural transition and became bicontinuous owing to progressive growth and interconnection of the O/IL microdomains. The further increase of cyclohexane resulted in a linear decrease of conductivity, which was interpreted as the consequence of the formation of IL/O microemulsions, suggesting inverse droplet aggregation appeared (Figures 4 and 5).

\section{FTIR of starch nanoparticles}

Figure 4a illustrates the FTIR spectra of native maize starch, OSA modified maize starch and starch nanoparticles. Compared with native maize starch, OSA modified maize starch showed two new absorption bands at 1570 and $1722 \mathrm{~cm}^{-1}$. The band occurring at $1570 \mathrm{~cm}^{-1}$ originated from asymmetric stretching vibration of carboxylate RCOO. The peak at $1722 \mathrm{~cm}^{-1}$ corresponded to $\mathrm{C}=\mathrm{O}$ stretching vibration of an ester group [30]. These bands certified the formation of esterification. 1158, $1081,1015 \mathrm{~cm}^{-1}$ were assigned to the $\mathrm{C}-\mathrm{O}$ bond stretching vibrations of anhydroglucose units, meanwhile, the $\mathrm{O}-\mathrm{H}$ stretching and $\mathrm{C}=\mathrm{H}$ stretching showed a strong signal at 3354 and $2931 \mathrm{~cm}^{-1}$, which is the same as native maize starch $[32,33]$. The spectra of starch nanoparticles exhibited some difference compared with OSA modified maize starch. The band of which at 3354 and $2931 \mathrm{~cm}^{-1}$ became narrow and moved to high frequency region. The reason might be that the crosslinking bonds replaced the O-H in starch. The peak at 1015, 1081 and 1158 $\mathrm{cm}^{-1}$ became stronger compared with OSA modified maize starch because of the formation of interior bonds in cross-link reaction. These data suggested the crosslinking reaction occurred between the starch molecules, and there are similar reports about FTIR spectrogram of starch microspheres.

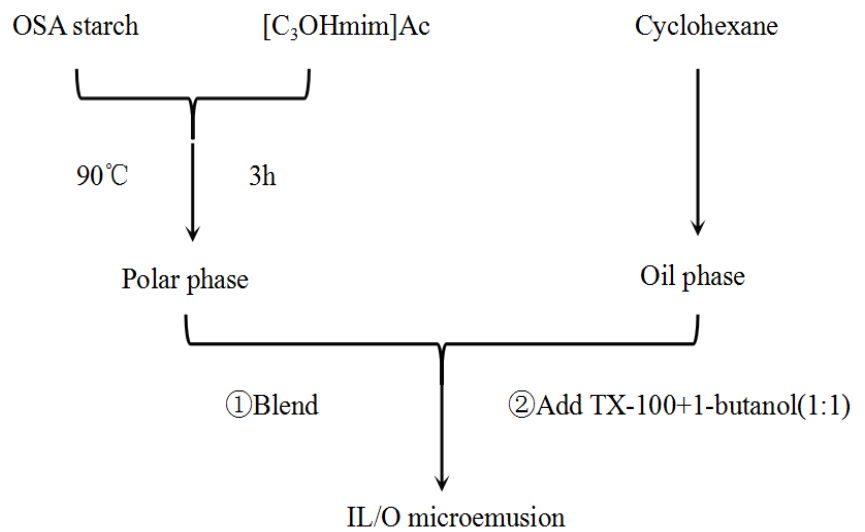

\begin{tabular}{l|l} 
(1)Add epichlorohydrin & (3)Washing \\
(2) Cetrifugation & (4) Drying
\end{tabular}

Starch nanoparticles

Figure 2: Preparation of starch nanoparticles. 
Citation: Zhigang L, Linrong S, Meina Z (2017) Preparation of Starch Nanoparticles in a New lonic Liquid-in-Oil Micro-emulsion. J Formul Sci Bioavailab 1: 116.
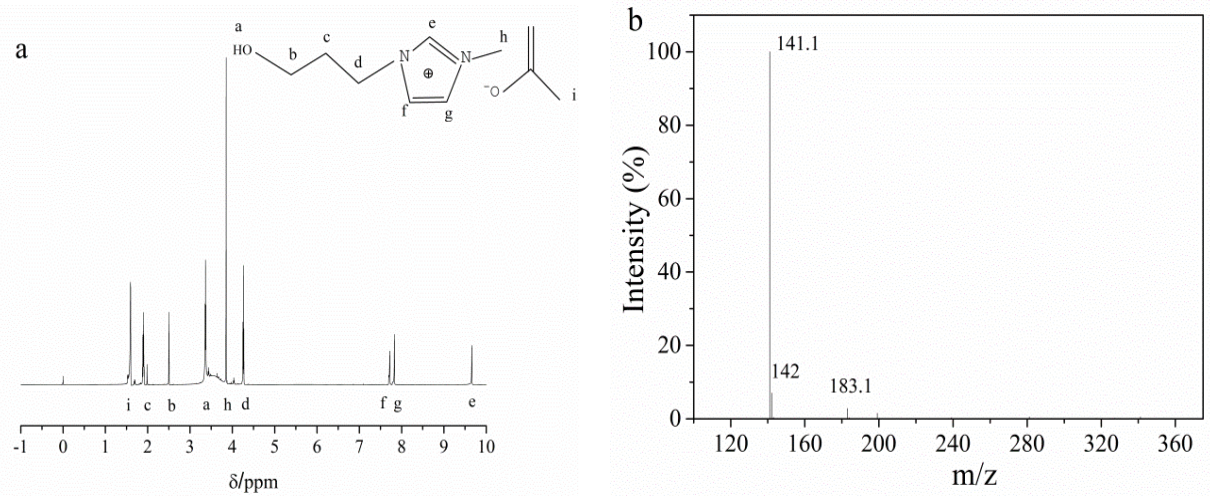

Figure 3: (a) ${ }^{1} \mathrm{H}$ NMR spectrum of $\left[\mathrm{C}_{3} \mathrm{OHmim}\right] \mathrm{Ac}$. (b) The ESI-MS spectrum of $\left[\mathrm{C}_{3} \mathrm{OHmim}\right] \mathrm{Ac}$ at positive ion mode.

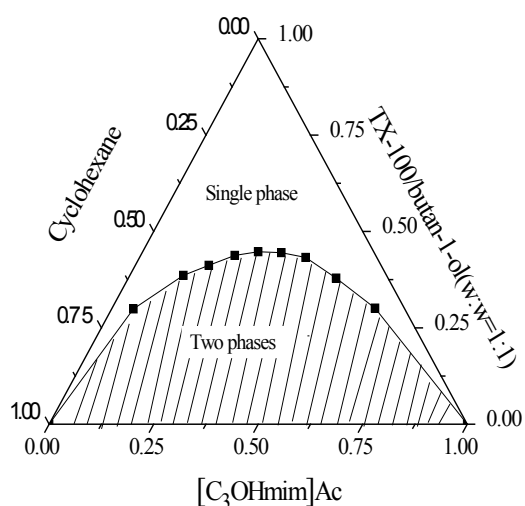

Figure 4: Phase diagram of $\left[\mathrm{C}_{3} \mathrm{OHmim}\right] \mathrm{Ac} / \mathrm{TX}-100+1$-butanol/cyclohexane at $25^{\circ} \mathrm{C}$.

X-ray diffraction (XRD) was used to study the crystalline structure of native maize starch, OSA modified maize starch and starch nanoparticles, as shown in Figure $4 \mathrm{~b}$. We observed that the native maize starch had no difference with OSA modified maize starch in the crystalline structure with the sharp diffraction peaks at $15.2^{\circ}$, $16.9^{\circ}, 18.1^{\circ}$ and $23.2^{\circ}$, showing a typical A-type pattern structure. This suggested that OSA modification had little effects on the crystalline structure. On the other hand, the spectrogram of starch nanoparticles showed a big broad peak, indicating that most of crystalline structure of the starch was probably destroyed into the amorphous shape due to the dissolution (Figure 6).

\section{Morphological analysis of starch nanoparticles}

Scanning electron microscopy (SEM) is an effective way to observe the morphology of particles. As seen from Figure 5, native maize starch had the similar morphology compared with OSA modified maize starch, the sizes varied from about 10 to $20 \mu \mathrm{m}$ and all of them were polygonal granules. Most of granules showed aggregation or cluster formation which could be mainly attributed to strong van der Waals force and electrostatic attraction, which was in line with Liu et al. [30] who also reported that starch granules congregated together. In comparison with these two starches, starch nanoparticles showed approximately spherical granules with fine dispersibility and were much smaller, their size and distribution of starch nanoparticles were analyzed by DLS technique as shown in Figure 7. The mean diameter of starch nanoparticles was $85.69 \mathrm{~nm}$ and the size distribution was relatively concentrated [31].

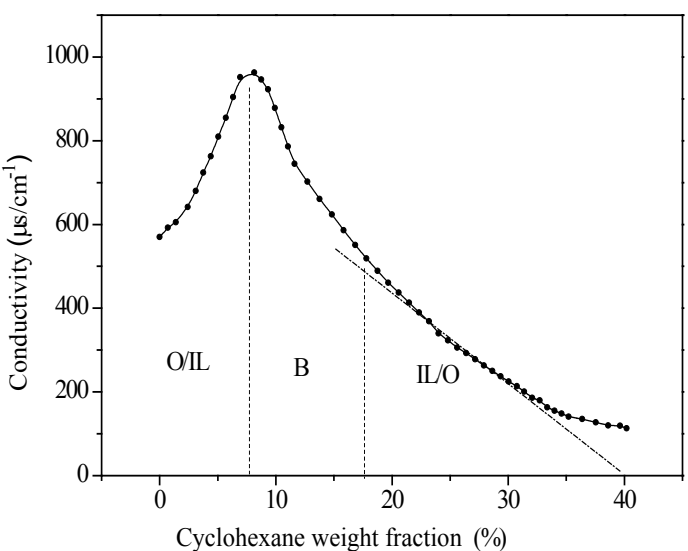

Figure 5: Electrical conductivity as a function of cyclohexane weight fraction in the microemulsion at $25^{\circ} \mathrm{C}$. $\left[\mathrm{C}_{3} \mathrm{OHmim}\right] \mathrm{Ac}$ : TX-100+1-butanol=1:4 $(\mathrm{w} / \mathrm{w})$, TX-100: 1 -butanol=1:1(w/w)

\section{Drug loading analysis}

The influence of loading time on drug loading property is shown in Figure 8a. The drug loading and encapsulation efficiency increased first and then decreased as time went on. To be exact, the drug loading increased from 1.12 to $2.63 \mathrm{mg} / \mathrm{g}$ as the time was prolonged from 0.5 to $2 \mathrm{~h}$ and then decreased to $2.26 \mathrm{mg} / \mathrm{g}$ when the time was extended to $2.5 \mathrm{~h}$. The encapsulation efficiency increased from 5.8 to $12.9 \%$ and then reduced to $11.8 \%$ correspondingly. From the result, it could be concluded that the drug loading and encapsulation efficiency of starch nanoparticles on indomathacin presented an appropriate time value. The effect of temperature on drug loading property is observed in Figure $8 \mathrm{~b}$. It was obvious that different loading temperatures resulted in significant changes in drug loading and encapsulation efficiency. At a temperature of $17^{\circ} \mathrm{C}$, starch nanoparticles loaded with more indomathacin and encapsulation efficiency showed the same trend. The reason for this phenomenon may be that the adsorption of indomathacin was mainly attributed to the existence of opposite charges and high affinity. This adsorption process would be hindered by high temperature; thus, the drug loading reduced at higher temperature. Starch nanoparticles with different particle sizes (86, 133, 187 and 263 $\mathrm{nm}$ ) were obtained through changing the reaction conditions such as reaction time, reaction temperature, and starch concentration to investigate the effect of particle size on drug loading property. As shown in Figure 8c, drug loading and encapsulation efficiency decreased with 
Citation: Zhigang L, Linrong S, Meina Z (2017) Preparation of Starch Nanoparticles in a New lonic Liquid-in-Oil Micro-emulsion. J Formul Sci Bioavailab 1: 116.
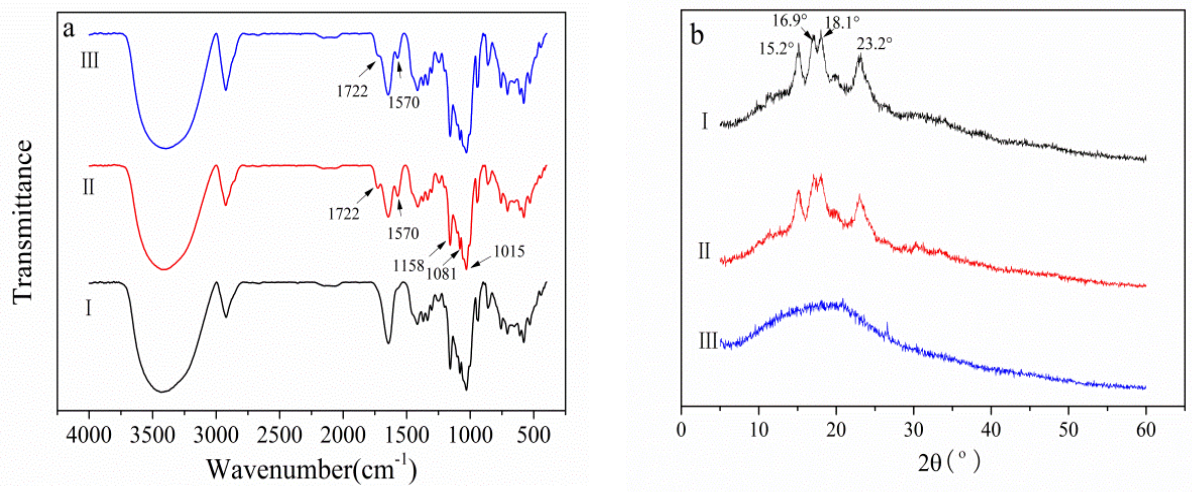

Figure 6: FTIR spectra (a) and XRD patterns (b) of native maize starch (I), OSA modified maize starch (II) and starch nanoparticles (III)
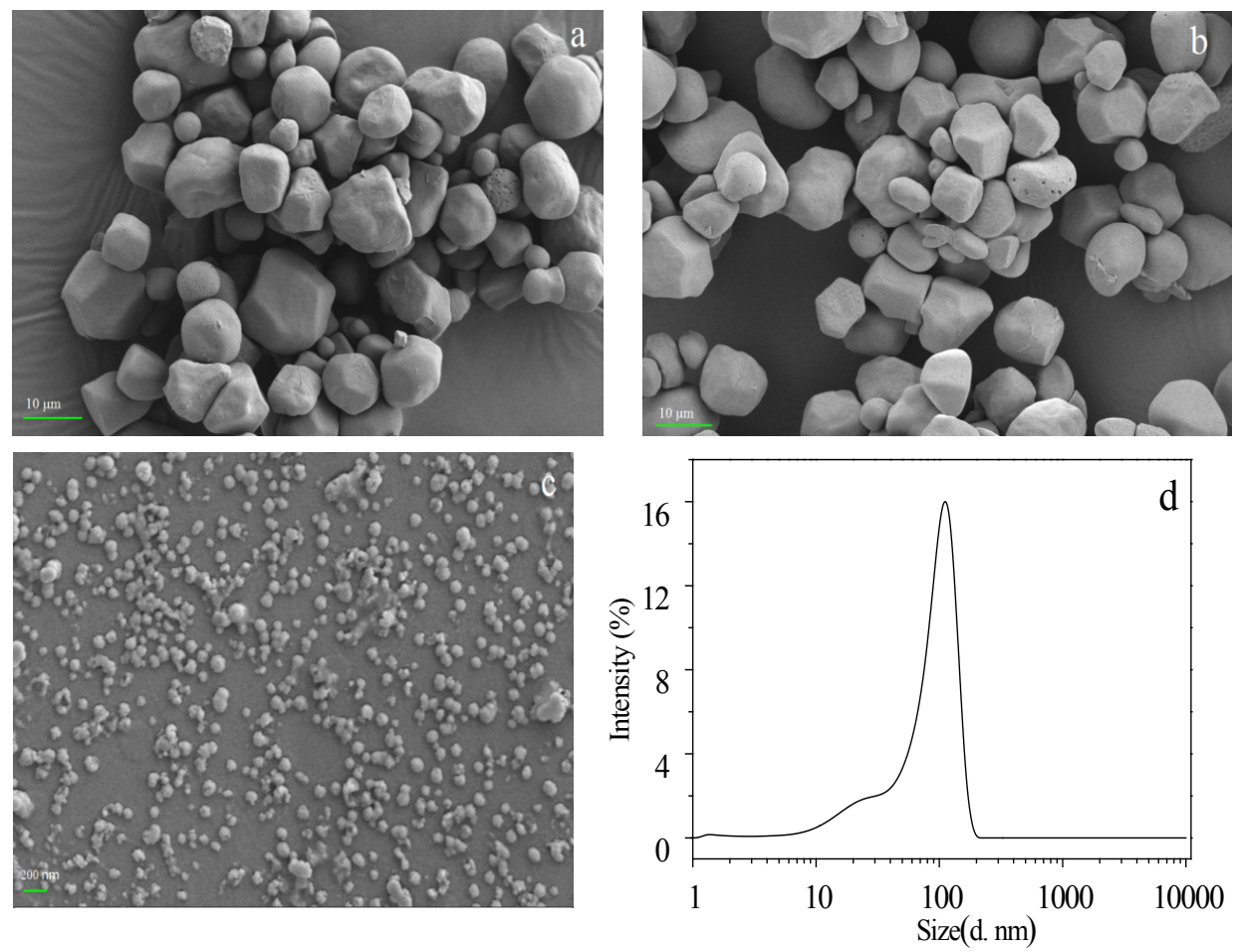

Figure 7: SEM images of native maize starch $(\times 1000, a)$, OSA modified maize starch $(\times 1000, b)$ and starch nanoparticles $(\times 20000, c)$ and the particle size and distribution of starch nanoparticles (d).

increasing particle size of starch nanoparticles. The reason for this phenomenon may be that starch nanoparticles of smaller particle size have greater specific surface area and stronger adhesion ability. As shown in Figure 8d, drug loading ascended significantly from 1.35 to $3.75 \mathrm{mg} / \mathrm{g}$ as the concentration of indomathacin rose from 0.02 to 0.08 $\mathrm{mg} / \mathrm{mL}$. However, the increase of drug concentration caused a decline in encapsulation efficiency. Therefore, higher drug concentration does not necessarily result in better drug loading property.

\section{Drug release analysis}

Drug release experiments were performed in PBS solution. As shown in Figure 9, initially, a burst release was observed in the first 1 $\mathrm{h}$ after the starch nanoparticles were immersed into the medium, high release rate of $74.32 \%$ was associated with the immediate dispersing of the indomathacin close to starch nanoparticles surfaces. In the following $2 \mathrm{~h}$, the starch nanoparticles formed a swelling-controlled and sustained release system, in which the release rate slowed down, and $89.75 \%$ of the indomathacin contained in the starch nanoparticles was released. This phenomenon was because on the one hand, indomathacin in the nanoparticles which occupied lots free volume spaces inside the swollen nanoparticles created tortuous paths to assist the transportation of water molecules, which facilitated starch nanoparticles to absorb water and swell sufficiently. On the other hand, increasing swelling impulsed a great number of indomathacin molecules to diffuse out of the starch nanoparticles and pass into the release medium through numerous pores and channels in the particles. However, as the nanoparticles swelled in PBS solution, a gel diffusion layer took shape gradually which hampered the outward expulsion of indomathacin and brought a sustained slowdown to the indomathacin release. From the 3 to $10 \mathrm{~h}$, drug release experienced a slight but slow rise. $94.52 \%$ of the indomathacin was released into PBS solution which kept almost unchanged in the next $10 \mathrm{~h}$. Since the pores 
Citation: Zhigang L, Linrong S, Meina Z (2017) Preparation of Starch Nanoparticles in a New lonic Liquid-in-Oil Micro-emulsion. J Formul Sci Bioavailab 1: 116.

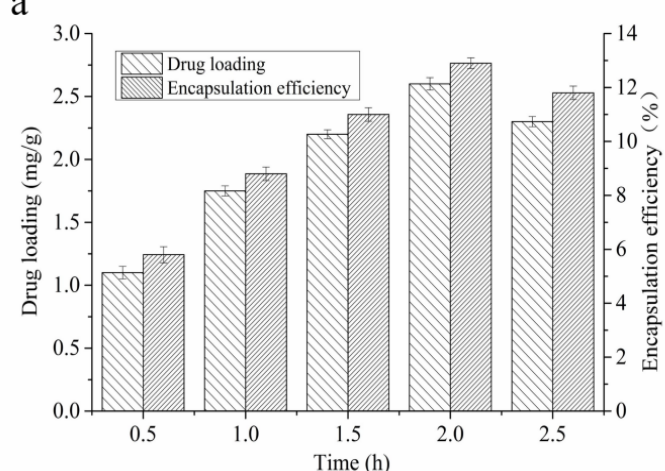

$\mathrm{c}$

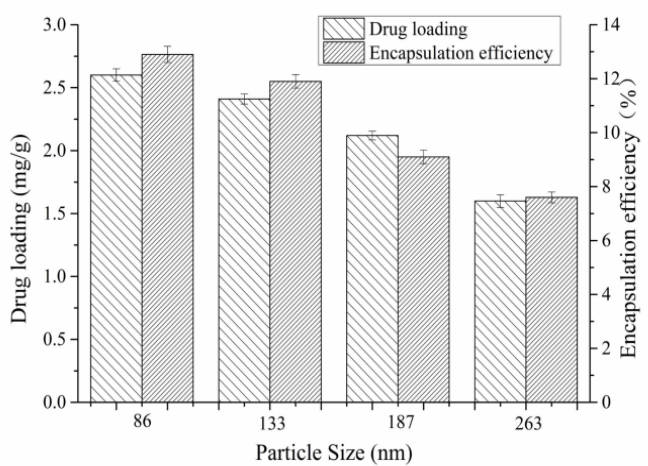

b

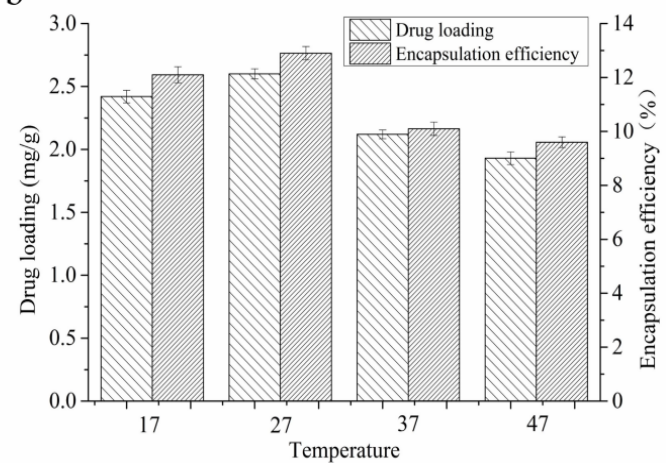

d

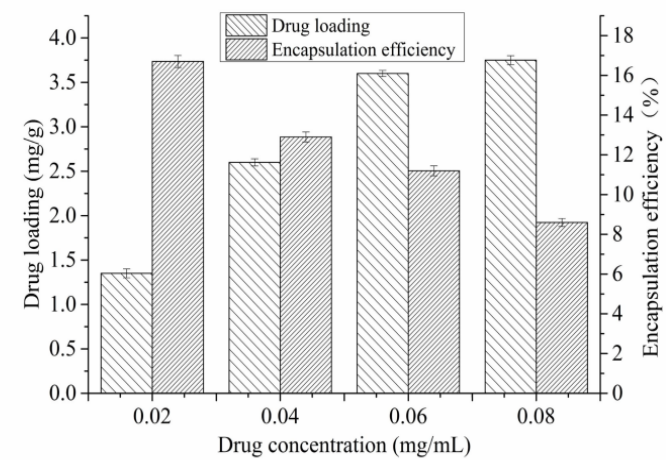

Figure 8: Effect of loading time (a), loading temperature (b), particle size (c), and drug concentration (d) on drug loading property. Other conditions: (a) loading temperature, $27^{\circ} \mathrm{C}$; particle size, $86 \mathrm{~nm}$; drug concentration, $0.05 \mathrm{mg} / \mathrm{mL}$. (b) Loading time, $2 \mathrm{~h}$; particle size, $86 \mathrm{~nm}$; drug concentration, $0.05 \mathrm{mg} /$ $\mathrm{mL}$. (c) Loading time, $2 \mathrm{~h}$; loading temperature, $27^{\circ} \mathrm{C}$; drug concentration, $0.05 \mathrm{mg} / \mathrm{mL}$; (d) loading time, $2 \mathrm{~h}$; loading temperature, $27^{\circ} \mathrm{C}$; particle size, $86 \mathrm{~nm}$.

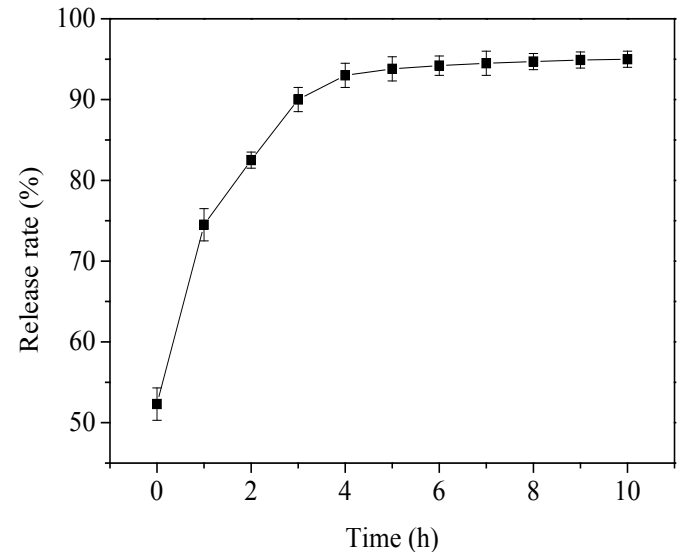

Figure 9: Indomathacin release of starch nanoparticles in PBS solution.

and channels for water transportation in the nanoparticles decreased dramatically as the gel diffusion layer enhanced, consequently less and less indomathacin was impelled out of the nanoparticles. Finally, the concentration of indomathacin reached a balance between starch microspheres and PBS solution as time was prolonged. However, tiny amount of indomathacin was released due to gradual but sluggish degradation of starch particles [33].

\section{Conclusions}

In our study, a new room-temperature ionic liquid $\left[\mathrm{C}_{3} \mathrm{OHmim}\right]$ Ac, based on imidazolium cation that contained additional functional group was synthesized to dissolve starch, and molecular structure of $\left[\mathrm{C}_{3} \mathrm{OHmim}\right] \mathrm{Ac}$ was confirmed by ${ }^{1} \mathrm{HNMR}$ and ESI-MS. Pseudo-ternary phase diagram conductivity were used to divide the micro region of micro-emulsion. Starch nanoparticles could be prepared based on this micro-emulsion system. FTIR data demonstrated the formation of crosslinking bonds between starch molecules. The spectrum of XRD showed that the crystal structure of starch was destroyed. SEM and DLS intuitively revealed that starch nanoparticles had good sphericity, small size and a relatively concentrated size distribution with the mean diameter was $105 \mathrm{~nm}$.

\section{Acknowledgements}

This research was supported by the National Natural Science Foundation of China $(21576098,21376097)$, the program for New Century Excellent Talents in University (NCET-13-0212), the Key Project of Science and Technology of Guangdong Province (2016A050502005, 2015A020209015, 2017B090901002) the Key Project of Science and Technology of Guangzhou City (201508020082), Project funded by China Postdoctoral Science Foundation (2016M590787, 2017T100616), and the Fundamental Research Funds for the Central Universities, SCUT (2015ZZ043).

\section{References}

1. Miao Z, Li Z, Deng D, Wang L, Liu Y (2010) Novel crosslinked starch microspheres as adsorbents of Cu2+ Journal of Applied Polymer Science 115: 487-490.

2. Hallett JP, Welton T (2002) Room-temperature ionic liquids: solvents for synthesis and catalysis. 2. Ionic liquids in synthesis. Wiley VCH Verlag 111: 3508-3576.

3. Dupont J, Souza RFD, Suarez PA (2002) Ionic Liquid (Molten Salt) Phase Organometallic Catalysis Chem Rev 102: 3667-3692.

4. Liu W, Budtova T (2013) Dissolution of unmodified waxy starch in ionic liquid and solution rheological properties. Carbohydr Polym 93: 199-206. 
Citation: Zhigang L, Linrong S, Meina Z (2017) Preparation of Starch Nanoparticles in a New lonic Liquid-in-Oil Micro-emulsion. J Formul Sci Bioavailab 1: 116.

5. Mazza M, Catana DA, Vaca-Garcia C, Cecutti C (2009) Supramolecular Polymer Network and Gels 16: 207-215.

6. Fujii K, Soejima Y, Kyoshoin Y, Fukuda S, Kanzaki R, et al. (2008) Electrochemistry in Ionic Liquids. J Phys Chem 112: 4329-4336.

7. Fujii K, Mitsugi T, Takamuku T, Yamaguchi T, Umebayashi Y, et al. (2009) Electro chemistry in lonic Liquids. Chem Lett 38: 340-341.

8. Jobling S (2004) Improving starch for food and industrial applications. Curr Opin Plant Biol 7: 210-218.

9. Raina C, Singh S, Bawa A, Saxena D (2007) A comparative study of Indian rice starches using different modification model solutions LWT. Food Sci Technol 40: 885-892.

10. Kim M, Lee SJ (2002) Textile Finishing: Recent Developments and Future Trends. Carbohydr Polym 50: 331-337.

11. Mundargi RC, Shelk BN, Rokhade AP, Patil SA, Aminabhavi TM (2008) Formulation and in-vitro evaluation of novel starch-based tableted microspheres for controlled release of ampicillin.Carbohydrate polymers 71: 42-53.

12. Sechia MSN, Marquesa TP (2017) Preparation and Physicochemical, Structural and Morphological Characterization of Phosphorylated Starch.

13. Malafaya P, Stappers F, Reis R (2006) Starch-based microspheres produced by emulsion crosslinking with a potential media dependent responsive behavior to be used as drug delivery carriers. J Mater Sci Mater Med 17: 371-377.

14. Mao S, Chen J, Wei Z, Liu H, Bi D (2004) Intranasal administration of melatonin starch microspheres. Int J Pharm 272: 37-43.

15. Gathergood N, Garcia MT, Scammells PJ (2004) Biodegradable ionic liquids: Part I. Concept, preliminary targets and evaluation. Green Chem 6: 166-175.

16. Gao H, Li J, Han B, Chen W, Zhang J, et al. (2004) Microemulsions with ionic liquid polar domains. Phys Chem 6: 2914-2916.

17. Gao Y, Han S, Han B, Li G, Shen D, et al. (2015) lonic Liquid-Based Surfactant Science lonic liquid-Based Surfactant Science. Langmuir 21: 5681-5684.

18. Yan F, Texter J (2006) Surfactant ionic liquid-based microemulsions for polymerization Chem. Commun. (Camb) 25: 2696-2698.

19. Zhang G, Zhou H, Hu J, Liu M, Kuang Y (2009) Ionic Liquid-Based Surfactant Science: Formulation, Characterization and Applications. Green Chem 11: 1428-1432.
20. Zhou G, Luo Z, Fuv X (2014) Preparation of Starch Nanoparticles in a Waterin-lonic Liquid Microemulsion System and Their Drug Loading and Releasing Properties. J Agric Food Chem 62: 8214-8220.

21. Zhou G, Luo Z, Fu X (2014) Industrial Crops and Products 52: 105-110.

22. Kim MJ, Choi SJ, Lim ST, Kim HK, Heo HJ, et al. (2007) Ferulic acid supplementation prevents trimethyltin-induced cognitive deficits in mice. Bioscience, Biotechnology and Biochemistry 71: 1063-1068.

23. Cheng X, Fu J, Liu J, Zhang Z, Zhang Y, et al. (2007) lonic Liquid-Based Surfactant Science. Colloid Surface A 302: 211-215.

24. Najjar R, Stubenrauch C (2009) Phase diagrams of microemulsions containing reducing agents and metal salts as bases for the synthesis of metallic nanoparticles. J Colloid Interface Sci 331: 214-220.

25. Wei J, Su B, Liang R, Xing H, Bao Z, et al. (2012) lonic Liquid-Based Surfactant Science. Colloid Surface A 414: 82-87.

26. Dvolaitzky M, Lagues M, Pesant LJ, Ober R, Sauterey C, et al. (1980) A structural description of microemulsions. Small-angle neutron scattering and electrical conductivity study. J Phys Chem 84: 1532-1535.

27. Zheng Y, Eli W, Li G (2009) FTIR study of Tween80/1-butyl-3-methylimidazolium hexafluorophosphate/toluene microemulsions. Colloid Polym Sci 287: 871-876.

28. Pramanik R, Ghatak C, Rao VG, Sarkar S, Sarkar N (2011) Room temperature ionic liquid in confined media: a temperature dependence solvation study in [bmim][BF4]/BHDC/benzene reverse micelles. J Phys Chem 115: 5971-5979.

29. Hong J, Zeng AX, Brennan SC, Brennan M, Han Z (2016) Recent Advances in Techniques for Starch Esters and the Applications: A Review. 5: 50.

30. Liu Z, Li Y, Cui F, Ping L, Song J, et al. (2008) Production of octenyl succinic anhydride-modified waxy corn starch and its characterization. J Agric Food Chem 56: 11499-11506.

31. Kačuráková M, Wilson RH (2001) Renewable Resources for Functional Polymers and Biomaterials. Carbohydr Polym 44: 291-303.

32. Mano JF, Koniarova D, Reis RL (2003) Thermal properties of thermoplastic starch/synthetic polymer blends with potential biomedical applicability. J Mater Sci: Mater Med 14: 127-135.

33. Li ZB, Wang JL, Li D, Adhikari B, Mao HZ (2012) Preparation and characterization of crosslinked starch microspheres using a two-stage waterin-water emulsion method. Carbohydr Polym 88: 912-916. 